\title{
Article \\ Investigation of the Detailed AMPylated Reaction Mechanism for the Huntingtin Yeast-Interacting Protein E Enzyme HYPE
}

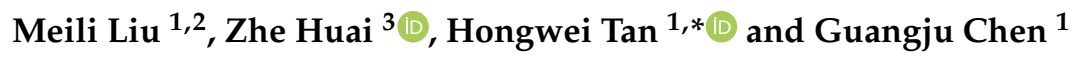 \\ 1 Department of Chemistry, Beijing Normal University, Beijing 100875, China; meililiu@berkeley.edu (M.L.); \\ gjchen@bnu.edu.cn (G.C.) \\ 2 Department of Chemical and Biomolecular Engineering, University of California, Berkeley, CA 94720, USA \\ 3 State Key Laboratory of Precision Spectroscopy, School of Physics and Electronic Science, East China Normal \\ University, Shanghai 200062, China; huaizhe123@163.com \\ * Correspondence: hongwei.tan@bnu.edu.cn
}

Citation: Liu, M.; Huai, Z.; Tan, H.; Chen, $\mathrm{G}$. Investigation of the Detailed AMPylated Reaction Mechanism for the Huntingtin Yeast-Interacting Protein E Enzyme HYPE. Int. J. Mol. Sci. 2021, 22, 6999. https://doi.org/ $10.3390 /$ ijms 22136999

Academic Editor: Stephan von Hörsten

Received: 1 June 2021

Accepted: 24 June 2021

Published: 29 June 2021

Publisher's Note: MDPI stays neutral with regard to jurisdictional claims in published maps and institutional affiliations.

Copyright: (c) 2021 by the authors. Licensee MDPI, Basel, Switzerland. This article is an open access article distributed under the terms and conditions of the Creative Commons Attribution (CC BY) license (https:/ / creativecommons.org/licenses/by/ $4.0 /)$
Abstract: AMPylation is a prevalent posttranslational modification that involves the addition of adenosine monophosphate (AMP) to proteins. Exactly how Huntingtin-associated yeast-interacting protein $\mathrm{E}$ (HYPE), as the first human protein, is involved in the transformation of the AMP moiety to its substrate target protein (the endoplasmic reticulum chaperone binding to immunoglobulin protein $(\mathrm{BiP})$ ) is still an open question. Additionally, a conserved glutamine plays a vital key role in the AMPylation reaction in most filamentation processes induced by the cAMP (Fic) protein. In the present work, the detailed catalytic AMPylation mechanisms in HYPE were determined based on the density functional theory (DFT) method. Molecular dynamics (MD) simulations were further used to investigate the exact role of the inhibitory glutamate. The metal center, $\mathrm{Mg}^{2+}$, in HYPE has been examined in various coordination configurations, including 4-coordrinated, 5-coordinated and 6-coordinated. DFT calculations revealed that the transformation of the AMP moiety of HYPE with $\mathrm{BiP}$ followed a sequential pathway. The model with a 4-coordinated metal center had a barrier of $14.7 \mathrm{kcal} / \mathrm{mol}$, which was consistent with the experimental value and lower than the $38.7 \mathrm{kcal} / \mathrm{mol}$ barrier of the model with a 6-coordinated metal center and the $31.1 \mathrm{kcal} / \mathrm{mol}$ barrier of the model with a 5-coordinated metal center. Furthermore, DFT results indicated that Thr518 residue oxygen directly attacks the phosphorus, while the His363 residue acts as H-bond acceptor. At the same time, an MD study indicated that Glu234 played an inhibitory role in the $\alpha$-inhibition helix by regulating the hydrogen bond interaction between Arg374 and the $\mathrm{P}_{\gamma}$ of the ATP molecule. The revealed sequential pathway and the inhibitory role of Glu234 in HYPE were inspirational for understanding the catalytic and inhibitory mechanisms of Fic-mediated AMP transfer, paving the way for further studies on the physiological role of Fic enzymes.

Keywords: density functional theory; AMPylation; Fic-mediated; HYPE

\section{Introduction}

Posttranslational modifications (PTMs) of proteins are an important cellular mechanism and typically used to alter diverse functions and locations such as signaling, localization or protein-protein interactions. The introduction of protein PTMs is a tightly controlled and almost ubiquitous process [1-5]. Modifications by proteases, kinases, methylases, and acetylases have been explored extensively, and their misregulation is often associated with severe pathology, including autoimmune diseases or cancer [6,7].

One such PTM common to Fic proteins that has recently been gaining attention is AMPylation (also referred to adenylation). AMPylation was first discovered in the 1960s as a regulatory mechanism for controlling glutamine synthetase activity in Escherichia coli [8]. Afterward, it was found that bacterial effectors from Vibrio parahaemolyticus and Histophilus somni AMPylate Rho guanosine triphosphatases (GTPases) were found to exist in human host cells $[9,10]$. These bacterial effectors contain highly conserved Fic domains, 
and the HXFX(D/E)GNGRXXR sequence motif, which uses ATP to covalently add an adenosine monophosphate (AMP) moiety to target proteins, and the most common and stable form of AMPylation occurs on the hydroxyl group of threonine, serine, or tyrosine through a phosphodiester bond [11]. The presence of a Fic domain is essential for AMP transfer $[12,13]$. Fic proteins include two critical elements that are the catalytic loop for the enzyme activity, and an inhibitory $\alpha$-helix $\left(\alpha_{\text {inh }}\right)$ for some Fic domains [14-16]. Despite their abundance in bacteria, only one human protein AMPylator containing the signature Fic domain, named Huntingtin yeast partner E (HYPE), was discovered and exhibited AMPylation activity against Cdc42, Rac1, and BiP in vitro [10,17-20].

HYPE is present in most cell types and tissues, although at low levels. Furthermore, HYPE is assumed to interact with Huntingtin, a protein that when mutated, causes Huntington disease [21], a neurodegenerative disorder. The catalytic loop in HYPE proteins shares the general signature motif of Fic domains, $\operatorname{HxFx}(\mathrm{D} / \mathrm{E})(\mathrm{A} / \mathrm{G}) \mathrm{N}(\mathrm{G} / \mathrm{K}) \mathrm{R}$, represented in HYPE by the sequence HPF(I/V)DGNGRT(S/A)R. The critical His residue within the catalytic motif corresponds to His363 in the human HYPE [18,22]. Interestingly, the catalytic activity of a group of Fic enzymes is regulated through the presence of an inhibitory $\alpha$-helix $\left(\alpha_{\text {inh }}\right)$. The inhibitory helix $\left(\alpha_{\text {inh }}\right)$ contains a common inhibitory signature, $(\mathrm{S} / \mathrm{T}) \times x \times E(G / N)$, conserved in HYPE proteins as (T/S)V(A/G)IEN. Inhibitory glutamate, Glu234, from $\alpha$-inh is positioned in the vicinity of the catalytic loop [20]. Conserved glutamate protrudes into the phosphate binding pocket of the catalytic site of Fic enzymes and thereby sterically and electrostatically obstructs ATP binding and phosphate positioning [20]. However, the mechanism of the release of inhibition is currently unknown.

Most of the known enzymes that catalyze AMPylation are bacterial effectors that are secreted into infected cells to AMPylate small GTPases (Rho and Rab families), and cause damage to the host cells $[9,23,24]$. These bacterial effectors are considered to be potential new targets for drug discovery because AMPylation plays an extraordinary role in infection [25]. Well-studied examples of Fic domain proteins are, for instance, VopS [26], AnkX [27] and IbpA [28], which catalyze AMPylation of Rho GTPases disrupting the actin cytoskeleton of the host cell. Experimental studies have found that HYPE is highly similar to the VopS protein which lacks $\alpha_{\text {inh }}[18,26,29]$. At the same time, BiP, one of the target proteins of HYPE, is a novel substrate for Drosophila mediated AMPylation. Furthermore, the experiments revealed that AMP attached to a single amino acid of BiP, number 518, a threonine residue [4].

Elucidating the mechanistic details of the AMPylation reaction has therefore been the subject of intensive research. Numerous experimental studies have been performed to explore the AMPylation reaction mechanisms of Fic proteins, such as the ping-pong mechanism [27,30,31] and sequential mechanism [26] (shown in Scheme 1). However, how HYPE achieves AMPylation remains an open question. Meanwhile, as a bifunctional enzyme of AMPylation and deAMPylation [1], detailed mechanistic studies of the role of HYPE in AMPylation may also help us understand the more complex problem of Fic protein's deAMPylation functions and provide theoretical insights to find more new Fic proteins and perform more possible research on Fic proteins.

In the present study, by employing the hybrid density functional theory (DFT) method B3LYP [32], we explored the catalytic mechanism of BiP catalyzed by the HYPE enzyme in detail. All transition states and stationary points along the reaction path were located. Our calculation results indicate that the HYPE enzyme used for the BiP target protein follows a sequential pathway, and its metal center, $\mathrm{Mg}^{2+}$, is 4-coordinated. In addition, we further investigated the exact role of the inhibitory glutamate Glu234 in $\alpha_{\text {inh }}$ by using molecular dynamics (MD) simulation to clarify the experimental observation that the glutamate residue on the inhibitory helix plays a key inhibitory effect. 


\section{(1) Ping-pong mechanism}

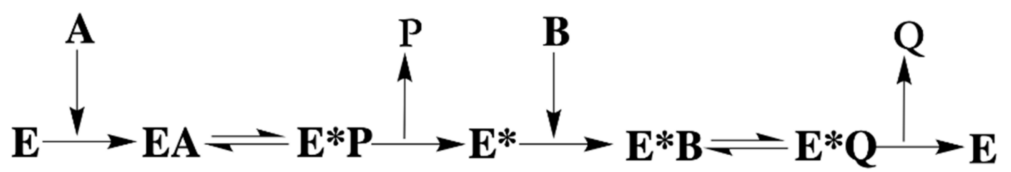

\section{(2) Sequential mechanism}

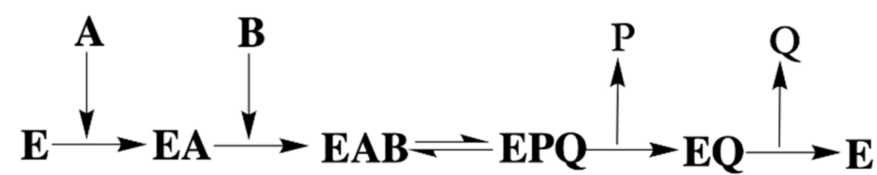

Scheme 1. Two reaction mechanisms in the Fic protein. (1) Ping-pong mechanism [27,30,31]. (2) Sequential mechanism [26]. E represents enzyme. A and B represent the different reactant substrate. $\mathrm{P}$ and $\mathrm{Q}$ are the products. EA are the binary complex. EAB and EPQ mean ternary complex.

\section{Results}

\subsection{AMPylation Mechanism of HYPE Complexed with BiP}

Three possible geometries for the binding of the two proteins, the HYPE protein and substrate BiP protein, were investigated. The schematic structures and the computed free energy profiles of the active site geometries of the reactant for the AMPylation reaction are depicted in Figure 1. In Figure 1 Model-1, the coordination number of $\mathrm{Mg}$ (II) ions is six, and the ligands are $\mathrm{P}_{\alpha}-\mathrm{O}, \mathrm{P}_{\beta}-\mathrm{O}, \mathrm{P}_{\gamma}-\mathrm{O}(\mathrm{ATP}), \mathrm{HOH}$, a negatively charged residue (Asp367 from HYPE), and a positively charged residue (Lys516 from the substrate BiP protein). The 5-coordinated geometry is shown in Figure 1 Model-2, with the ligands $\mathrm{P}_{\alpha}-\mathrm{O}, \mathrm{P}_{\beta}-\mathrm{O}(\mathrm{ATP})$, $\mathrm{HOH}$, a negatively charged residue (Asp367 from HYPE), and a positively charged residue (Lys516 from the substrate target protein, $\mathrm{BiP}$ ). $\mathrm{A} \mathrm{Mg}^{2+}$ ion in the E234A variant of HYPE bridges the $\alpha$ - and $\beta$-phosphates and is coordinated by the conserved Asp367 side chain. The conserved arginine at the C-terminal side of the Fic catalytic loop, Arg374, forms hydrogen bonds with the ribose ring and is also critical for binding $\gamma$-phosphate. Figure 1 Model-3 shows the geometries of 4-coordinated $\mathrm{Mg}(\mathrm{II})$ ions complexed with $\mathrm{P}_{\alpha}-\mathrm{O}, \mathrm{P}_{\beta}-\mathrm{O}$, $\mathrm{P}_{\gamma}-\mathrm{O}(\mathrm{ATP})$ and Asp367.

The calculated energetic data are listed in Figure 1a-c. The 4-coordinated model is favorable, with an energy barrier of $14.7 \mathrm{kcal} / \mathrm{mol}$, while the 5-coordinated model and hexacoordinated model experience TSs with energy barriers of $31.1 \mathrm{kcal} / \mathrm{mol}$ and $38.7 \mathrm{kcal} / \mathrm{mol}$, respectively. Meanwhile, they are endothermic reactions for Model-1 and Model-2 (Figure 1a,b). An exothermic reaction easily occurs for Model-1 (Figure 1c). HYPE was the first human Fic protein, sequence analysis revealed that HYPE shared some similarities with VopS [33]. To easily understand the differences between the sequences of the HYPE protein and VopS protein, we made Scheme S1. Key amino acids of the active site motif (His) and inhibitory motif (Glu) are highlighted in red and green, respectively. The Fic domain (represented by a gray circle) is essential for AMP transfer. Compared with VopS, HYPE has a Fic motif and $\alpha_{\text {inh }}$ in the Fic domain, while VopS has a Fic motif. The Glu234Ala mutation in our calculations uses the Ala234 residue to replace the key residue Glu234 in $\alpha_{\text {inh. }}$. Therefore, we further compared our results with the kinetic constant measurements of VopS [26]. The apparent kinetic constants measured for the ATP of wild-type VopS [26] were $26 \pm 1.0 \mathrm{~s}^{-1}$ (approximately $15 \mathrm{kcal} / \mathrm{mol}$ ), which is consistent with the $14.7 \mathrm{kcal} / \mathrm{mol}$ constant obtained from Model-3. 

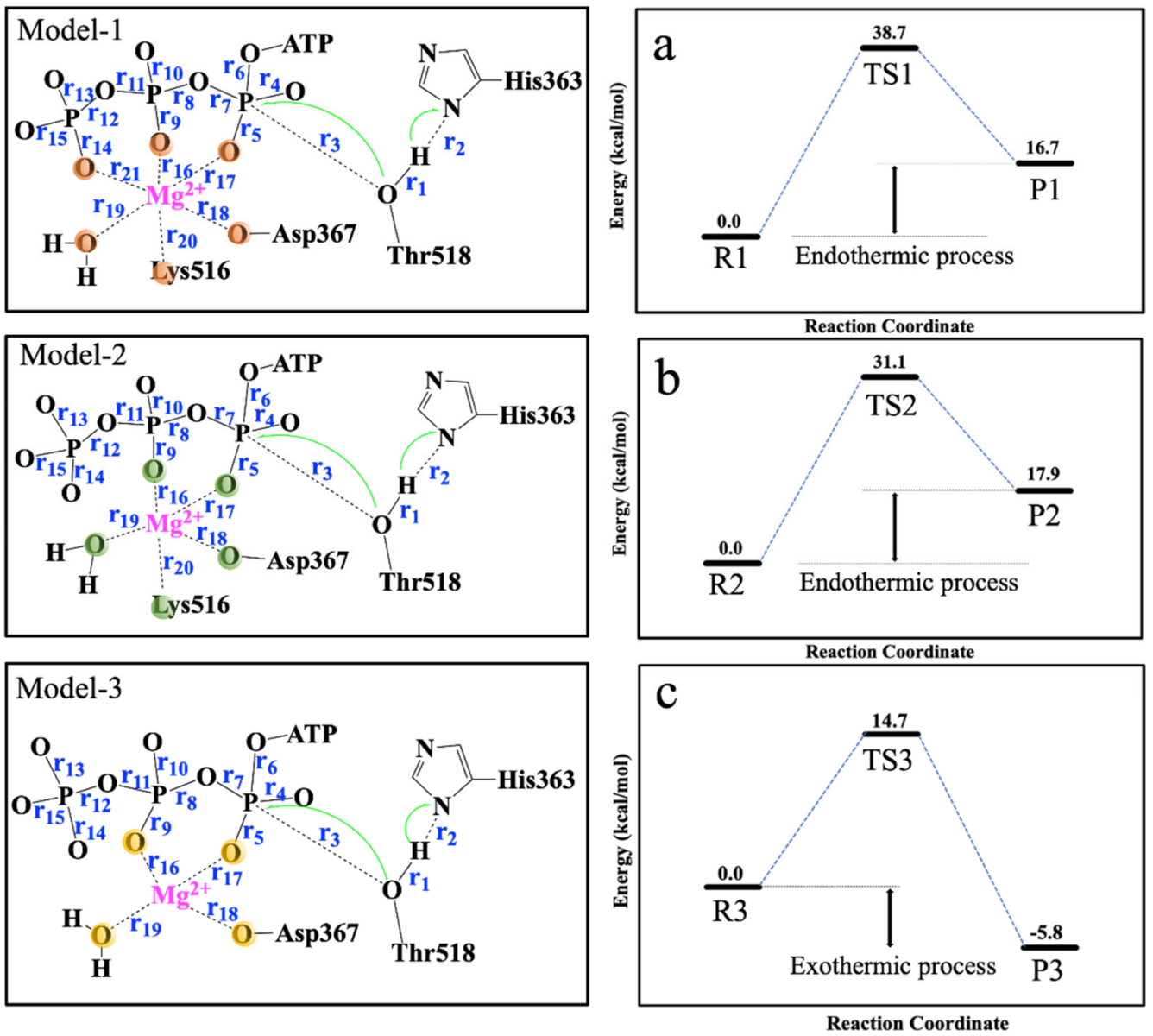

Figure 1. Free energy profiles along with the representative structures of the reactant $(\mathrm{R})$, transition state (TS) and product (P) of AMPylation for the HYPE protein complexed with the BiP protein. (a) 6-coordinated, (b) 5-coordinated, (c) 4-coordianted. For clarity, the coordination details of $\mathrm{Mg}^{2+}$ are shown (Model-1, Model-2 and Model-3).

Scheme 1 shows the details of the ping-pong mechanism and a sequential reaction mechanism. The largest feature is the ternary complex in the sequential mechanism. From this point on, three geometries in our calculations all supported the sequential mechanism (ternary complex (EAB), shown in Scheme 1(2)), indicating that the HYPE protein would interact with both ATP and the substrate BiP protein to allow transfer of the AMP group to the threonine residue.

As listed in Table 1, three coordinated species, 6-coordinated, 5-coordinated and 4coordinated species, were located and the coordinate details are shown in table S-S6. For inspection of the bond lengths in Table 1, r16, r17, r18, r19, r20, and r21 (Figure 1 Model-1, Model-2, and Model-3) represent the changes in the bond length of the coordination bond for the stationary points. The changes are small. $\mathrm{r} 1\left(\mathrm{O}_{\mathrm{Thr} 518}-\mathrm{H}_{\mathrm{Thr} 518}\right), \mathrm{r} 2\left(\mathrm{~N}_{\mathrm{His} 363}-\mathrm{H}_{\mathrm{Thr} 518}\right)$, $\mathrm{r} 3\left(\mathrm{P}_{\alpha}-\mathrm{O}_{\text {Thr518 }}\right)$, and $\mathrm{r} 7\left(\mathrm{P}_{\alpha}-\mathrm{O}_{\alpha \beta}\right)$ are closely related to the AMPylation reaction process (see Figure 1 Model-1, Model-2, Model-3). We focus on the distances of r1, r2, r3 and r7 shown in Figure 2 in the reactant, TS and product. Notably, r1 and r2 are $1.74 \AA$ and $1.90 \AA$ in TS1 and TS2 and $2.10 \AA$ and $2.10 \AA$ in $\mathrm{P} 1$ and P2, respectively. In contrast, $\mathrm{r} 1$ and $\mathrm{r} 2$ are $1.02 \AA$ in TS3 and $1.83 \AA$ in P3. When going from the reactant to the product, experimental researchers proposed [34] that the His residue, as a general base, abstracts the proton from the hydroxyl group of the Thr residue by forming a $\mathrm{N}_{\mathrm{His}}-\mathrm{H}_{\mathrm{Thr}}$ bond, which is accompanied by the breakage of the $\mathrm{O}_{T h r}-\mathrm{H}_{T h r}$ bond. At the same time, the $\mathrm{P}_{\alpha}-\mathrm{O}_{\alpha \beta}$ bond breaks down from the reactant to product states. Additionally, a $\mathrm{P}_{\alpha}-\mathrm{O}_{\mathrm{Thr} 518}$ bond formed. It was involved in the 6-coordinated and 5-coordinated species in this work. Interestingly, 
His363 on Model-3 with magnesium coordinated by Asp367 and HOH606 interacts with $\beta$-phosphate, and the $\gamma$-phosphate of ATP acts as an acceptor to accept a proton from the hydroxyl group of the Thr518 residue of the BiP protein. Thus, our calculations predict that (a) the proton transfer processes in the two models of 6-coordination and 5-coordination are nearly complete in the TS and that $(b)$ the formation of $\mathrm{P}_{\alpha}-\mathrm{O}_{\text {Thr518 }}$ and the breakage of $\mathrm{O}_{\text {Thr518 }}-\mathrm{H}_{\text {Thr518 }}$ occur after proton transfer.

Table 1. Important bond lengths (angstrom) in reactant, transition state and product of AMPylated reaction. $\mathrm{r} 1, \mathrm{r} 2, \mathrm{r} 3$ and $\mathrm{r} 7$ are the dominant reactive bond. $\mathrm{r} 16, \mathrm{r} 17, \mathrm{r} 18, \mathrm{r} 19, \mathrm{r} 20$ and $\mathrm{r} 21$ are coordinated bonds. (denoted in Figure 2).

\begin{tabular}{|c|c|c|c|c|c|c|c|c|c|}
\hline & \multicolumn{3}{|c|}{ Model_1 (Coord-6) } & \multicolumn{3}{|c|}{ Model_2 (Coord-5) } & \multicolumn{3}{|c|}{ Model_3 (Coord-4) } \\
\hline & R1 & TS1 & P1 & $\mathbf{R 2}$ & TS2 & P2 & R3 & TS3 & P3 \\
\hline r1 & 1.00 & 1.74 & 2.10 & 1.00 & 1.90 & 2.10 & 0.98 & 1.02 & 1.83 \\
\hline r2 & 1.82 & 1.07 & 1.02 & 1.82 & 1.05 & 1.02 & 1.87 & 1.68 & 1.03 \\
\hline r3 & 4.43 & 2.20 & 1.71 & 4.40 & 2.03 & 1.70 & 3.82 & 2.02 & 1.66 \\
\hline $\mathrm{r} 4$ & 1.50 & 1.49 & 1.49 & 1.50 & 1.51 & 1.49 & 1.51 & 1.51 & 1.51 \\
\hline r5 & 1.52 & 1.51 & 1.52 & 1.53 & 1.56 & 1.53 & 1.52 & 1.51 & 1.52 \\
\hline r6 & 1.62 & 1.62 & 1.64 & 1.61 & 1.66 & 1.63 & 1.59 & 1.60 & 1.63 \\
\hline $\mathrm{r} 7$ & 1.65 & 2.13 & 3.20 & 1.64 & 1.89 & 2.96 & 1.66 & 2.10 & 3.25 \\
\hline r8 & 1.64 & 1.55 & 1.52 & 1.67 & 1.57 & 1.51 & 1.65 & 1.57 & 1.54 \\
\hline r9 & 1.53 & 1.56 & 1.57 & 1.54 & 1.56 & 1.59 & 1.54 & 1.55 & 1.55 \\
\hline r10 & 1.49 & 1.51 & 1.52 & 1.49 & 1.50 & 1.52 & 1.50 & 1.52 & 1.53 \\
\hline r11 & 1.64 & 1.70 & 1.72 & 1.62 & 1.65 & 1.69 & 1.60 & 1.63 & 1.64 \\
\hline r12 & 1.67 & 1.62 & 1.62 & 1.69 & 1.66 & 1.63 & 1.70 & 1.67 & 1.65 \\
\hline r13 & 1.53 & 1.55 & 1.55 & 1.55 & 1.56 & 1.57 & 1.53 & 1.53 & 1.54 \\
\hline r14 & 1.55 & 1.56 & 1.56 & 1.54 & 1.55 & 1.56 & 1.53 & 1.53 & 1.53 \\
\hline r15 & 1.55 & 1.55 & 1.55 & 1.52 & 1.53 & 1.53 & 1.53 & 1.53 & 1.54 \\
\hline r16 & 2.14 & 2.04 & 2.05 & 2.06 & 2.02 & 1.98 & 1.97 & 1.94 & 1.94 \\
\hline r17 & 2.05 & 2.10 & 2.17 & 2.04 & 2.04 & 2.09 & 1.96 & 1.97 & 1.96 \\
\hline r18 & 2.08 & 2.05 & 2.06 & 1.95 & 2.00 & 1.98 & 1.92 & 1.93 & 1.94 \\
\hline r19 & 2.14 & 2.11 & 2.16 & 2.11 & 2.12 & 2.12 & 2.00 & 2.01 & 2.01 \\
\hline r20 & 2.04 & 2.06 & 2.12 & 2.02 & 2.06 & 2.05 & - & - & - \\
\hline r21 & 1.55 & 2.12 & 2.12 & - & - & - & - & - & - \\
\hline
\end{tabular}

Additionally, in the 4-coordination model, proton transfer between His363 and Th518 is completed later, and the transition state is reached. In considering computed free energy profiles, later proton transfer $(14.7 \mathrm{kcal} / \mathrm{mol})$ is favored in the AMPylation reaction of HYPE. Furthermore, the electrostatic potentials (ESPs) [35] on the molecular vdW surface of the reactants for the three models are visualized in Figure S1. The yellow and magenta spheres represent the surface local maxima and minima of the ESP. The ESP values encircling $\mathrm{P}_{\alpha}$ are positive for the 4-coordinated model (Table S3), while the ESP values are negative for the 6-coordinated (Table S1) and 5-coordinated models (Table S2). This helps us understand the phenomenon that His 363 acts as an acceptor instead of a general base in model-3 with 4-coordinated $\mathrm{Mg}^{2+}$ during the AMPylation process. 


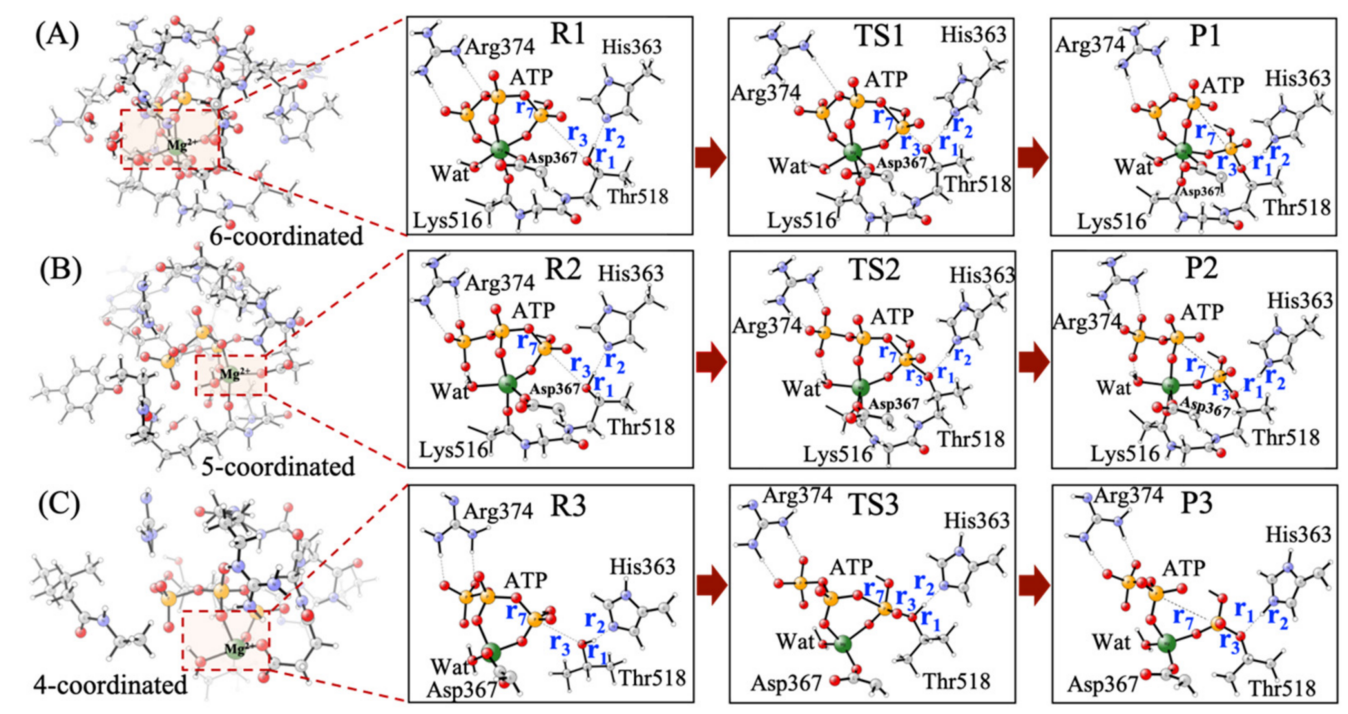

Figure 2. Reactant, TS and product of AMPylation between HYPE protein and substrate BiP protein. Three lines (A, B and C) are corresponding to the 6-coordinated, 5-coordinated and 4-coordinated, respectively. Some residues are not shown for clarity. Atom color code used, $\mathrm{P}$ (orange), $\mathrm{Mg}^{2+}$ (green), $\mathrm{O}$ (red), N (blue), C (grey) and H (white).

\subsection{The Exact Role of Glu234 in AMPlation}

Previous experimental evidence indicated that inhibitory glutamate in the inhibitory $\alpha$-helix plays a vital role. To gain further insight into the detailed role of the inhibitory glutamate, we carried out a detailed analysis of its functional and structural role. As shown in Figure S2, during the $70 \mathrm{~ns}$ MD simulation, the average root-mean-square deviation (RMSD) of the whole protein complexes and the ATP molecule at approximately $5 \AA$ in complexes with Glu234 and Glu234Ala converged well, indicating that stable models in HYPE complexed with BiP. Figure 3 depicts the interaction map of equilibrated structures for two geometries with Glu234 (Figure 3a, Glu234) and with Glu234Ala (Figure 3b, Ala234). We can identify important residues contributing to favorable interactions. The interaction map of Figure 3a tells us that Gly368, Asn369, Gly370 and Leu403 form stable hydrogen bonds with ATP molecules. The corresponding mutated structures in Figure $3 \mathrm{~b}$ show that Arg374, Gly370, Arg371, Lys534, Gly368, Asn369, Tyr399 and Hie356 form stable hydrogen bonds with ATP molecules. Note that in Figure 3a, Arg371 formed two interactions with $\mathrm{O}_{\beta}$ and $\mathrm{O}_{\gamma}$, and $\mathrm{Arg} 374$ had only one interaction with $\mathrm{O}_{\beta}$. The interactions include salt bridge interactions and no Pi-Pi stacked interactions. In Figure $3 b, \operatorname{Arg} 371$ also interacts with $\mathrm{O}_{\beta}$ and $\mathrm{O}_{\gamma}$; at the same time, Arg374 has two interactions with $\mathrm{O}_{\gamma}$ (Figure $3 \mathrm{~b}$ and Figure S6). In contrast, the interactions include Pi-Pi stacked interactions and no salt bridge interactions. The two structures are very similar so that the interaction maps of the two are also similar. However, the mutated structure (Figure 3b) is more stable according to the interaction map. Figure S4 shows the number of hydrogen bonds between the ATP molecule and the surrounding residues. The average number of hydrogen bonds surrounded by ATP molecule is 9.3 for the mutated structure, Ala234, and 5.2 for the structure with Glu234. This further revealed that the ATP molecule has a more stable environment in the mutated structure, Ala234, than in the structure with Glu234. 

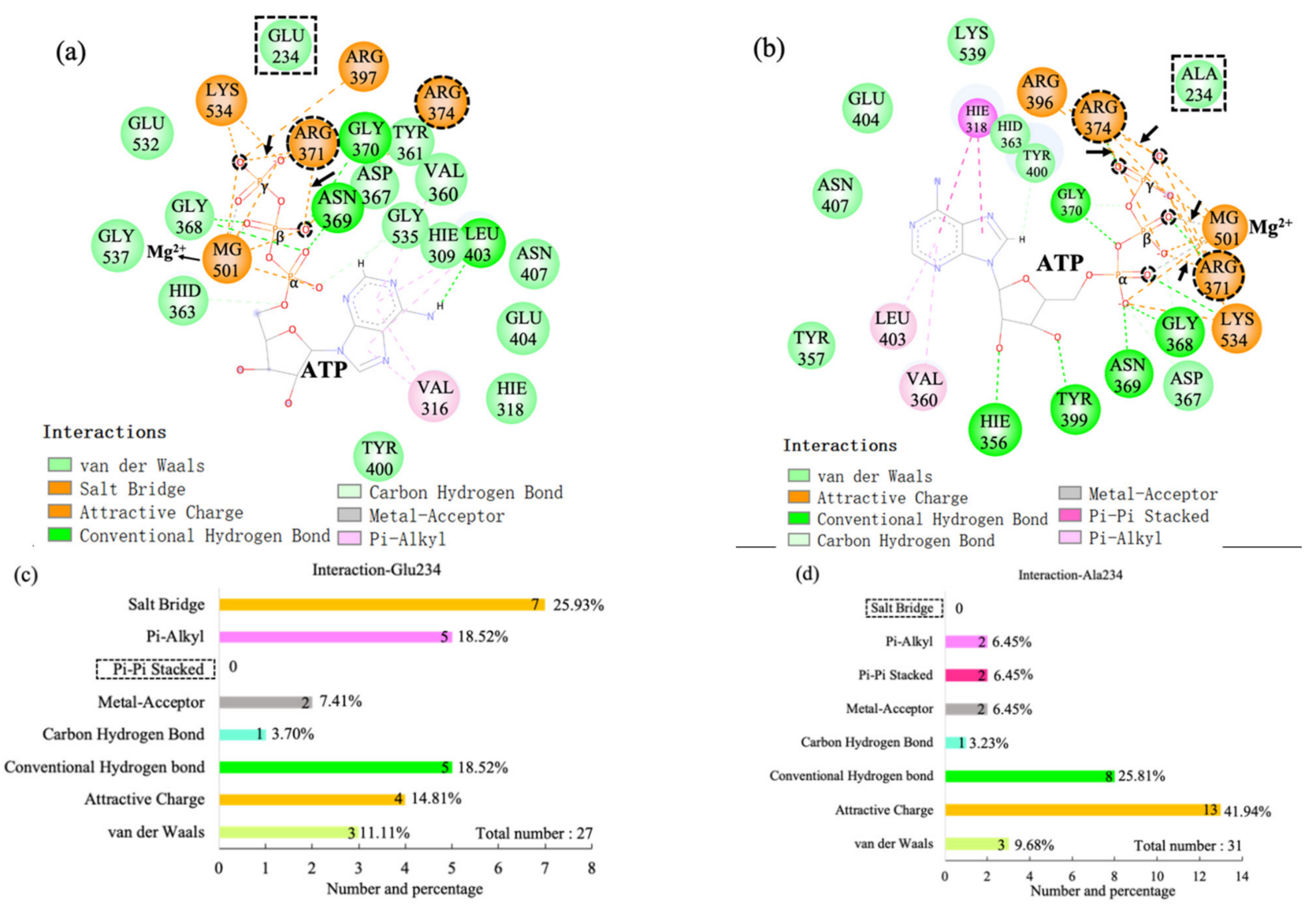

Figure 3. Interaction maps for HYPE protein complexed with BiP protein, obtained from equilibrated structures. (a) for Glu234; (b) for Ala234; (c) represents the analysis details of interaction of Glu234 in (a); (d) represents the analysis of interaction of Ala234 in (b). The black arrow in $(\mathbf{a}, \mathbf{b})$ are the interaction between Arginine residue and ATP. (a,b) made by Discovery Studio Visualizer, and (c,d) were obtained by the excel software.

The root-mean-squared fluctuation (RMSF) of C- $\alpha$ atoms was calculated for two geometries, the results of which are shown in Figure S3. The RMSF plots of the two complexes, except for several parts of the complexes, are similar, which indicates that the interactions between ATP and the surrounding residues of the complexes are similar. For example, we can find a large conformational fluctuation around residue 374. To clarify the difference in details, we checked the geometries using the equilibrium structures. Figure 4a shows the superimposition of the active sites in Glu234 (Figure 4b) and Glu234Ala (Figure 4c). From the geometries, we know that Arg374 forms a hydrogen bond with Glu234 when Glu234 exists (Figure 4b). When Glu234 is replaced by Ala234, the $\mathrm{O}_{\gamma}-\mathrm{P}$ of ATP molecules has a hydrogen interaction with Arg374 (Figure 4c and Figure S6). Therefore, we can conclude that the hydrogen interaction between the Arg374 and $\mathrm{O}_{\gamma}-\mathrm{P}$ of ATP molecules favors the transformation of the AMP group. Glu234 inhibited the AMPylation of the HYPE protein with the BiP protein by controlling the hydrogen interaction of the Arg374 residue. Meanwhile, the position of the inhibitory glutamate (Glu234) in the structure of wild-type HYPE is consistent with its role in competing with the Arg374/ $\gamma$-phosphate interaction (Figure 4). Arginine enters the active site of HYPE to stabilize the transition state of the phosphoryl transfer reaction. 


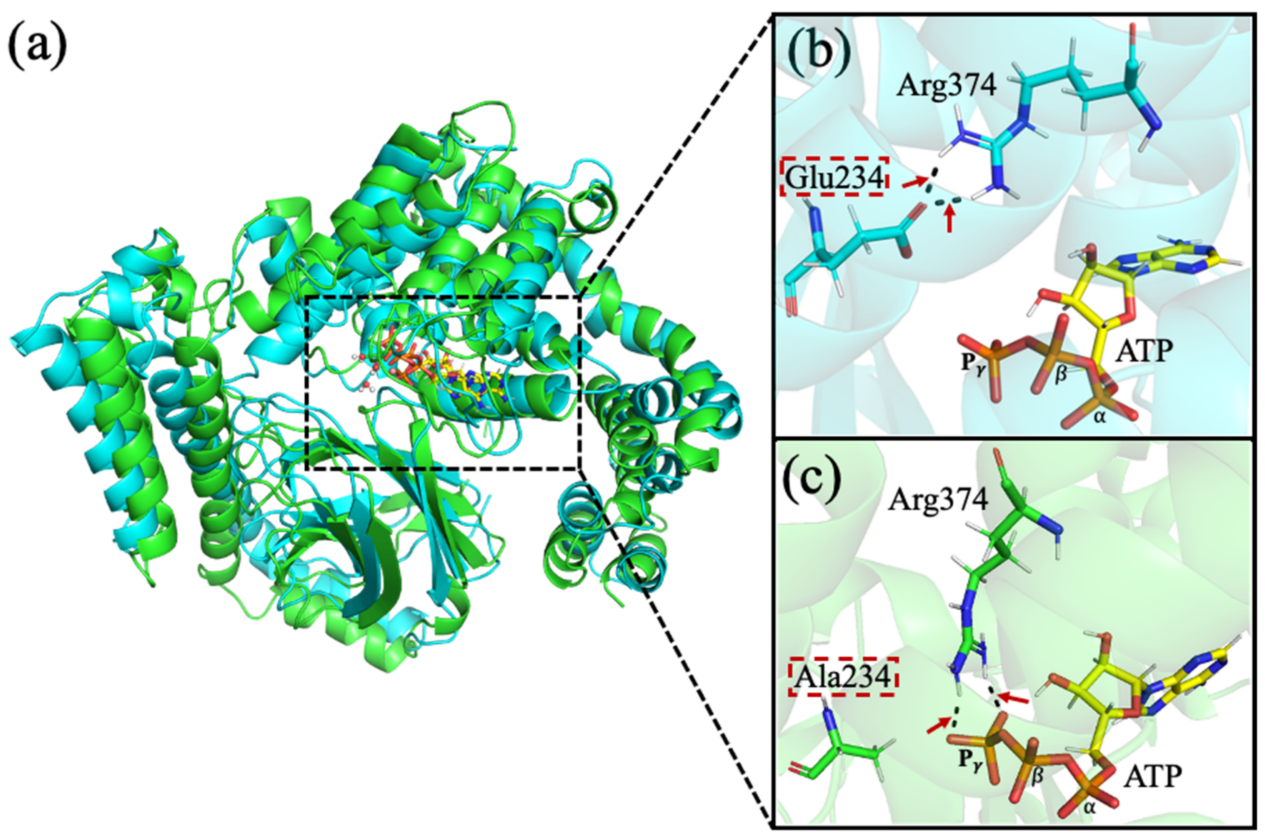

Figure 4. (a) Superimposition of MD equilibrated structures between HYPE-BiP with Glu234 complex (cyan) and HYPE-BiP with Ala234 complex (green). (b,c) Partial enlarged view of the area indicated by the dotted box in (a). (b) HYPE-BiP complex with Glu234 (arrow in (b,c) HYPE-BiP complex with Ala234 (arrow in (c)). Hydrogen bonds are denoted with yellow dashed lines and coordinated bonds are denoted with black dashed lines. Binding site residues are shown as sticks and are colored according to the chain of origin. Atom color code used, $\mathrm{Mg}^{2+}$ (pink), C (yellow) in ATP, P (orange), $\mathrm{O}$ (red), $\mathrm{N}$ (blue) and $\mathrm{H}$ (white). Asterisks denoted residues that originate from the substrate BiP protein, other residues are from the HYPE protein.

\section{Discussion}

DFT calculations were employed to systematically study the mechanism by which HYPE catalyzed the targeted BiP protein. The calculation results suggest that HYPE utilized a sequential (ternary complex) mechanism to AMPylate the target BiP protein. The His363 residue played a critical role in the AMPylation reaction to accept the proton from Thr518 instead of abstracting the proton of Thr518 in the substrate BiP protein. The structural comparison of TS1, TS2 and TS3 (Figure 2) in this work also confirmed the importance of proton transmission in His363 residues. In addition, we discovered that $\mathrm{Mg}^{2+}$ coordinated with ATP molecules in the HYPE protein via 4-coordination, and the corresponding energy barrier is $14.7 \mathrm{kcal} / \mathrm{mol}$, which is consistent with experimental value and favors the AMPylation of the HYPE protein complexed with the targeted BiP protein.

Experimental researchers have reported that Glu234 plays a key role [20] in inhibiting the AMPylation reaction of the HYPE protein with the BiP protein. In this work, a series of classical MD simulations of HYPE complexed with BiP provided insight into the exact role of inhibitory glutamate in forming hydrogen bond interactions with Arg374, resulting in an unfavorable geometry for the AMPylation reaction when glutamate exists. When glutamate was mutated into alanine, the Arg374 salt bridge ion paired with Arg374 would be broken so that $\mathrm{O}_{\gamma}-\mathrm{P}$ would have a stable hydrogen interaction (Figure $4 \mathrm{c}$ and Figure S6) with Arg374, which favors the AMPylation reaction.

A different hydrogen interaction environment is mainly the possible reason mentioned several times in the experiment $[20,33]$. Our results also have a better understanding for the regulation process of HYPE protein and BiP protein. As shown in Figure 5a,b, Glu234 affects the coordination number of the metal center by changing the hydrogen interaction mode between amino acid 234 and $\mathrm{O}_{\gamma}$-P or Arg374 residue, thereby changing the charge and interaction environment of the active center, and ultimately controlling the transfer of protons in His363, thereby controlling the AMPylation reaction. 
(a)

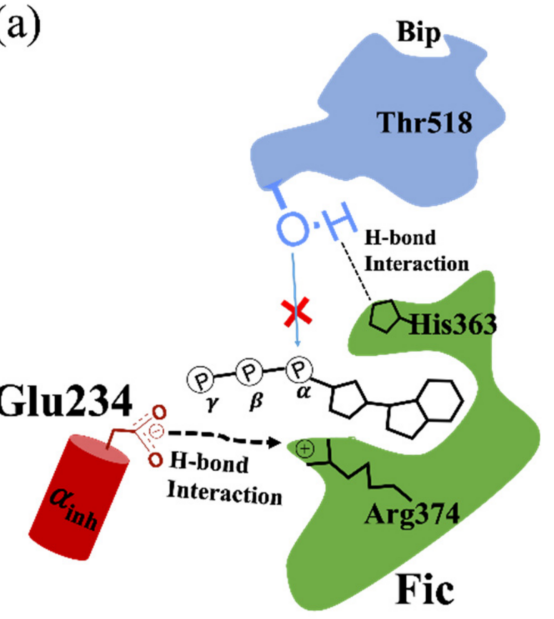

(b)

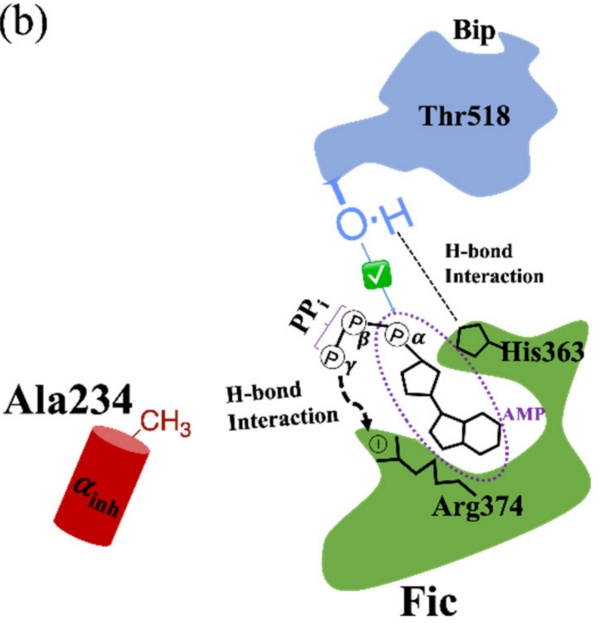

Figure 5. The general inhibition mechanism of Glu234 in HYPE with the target BiP protein. (a) for Glu234 (b) for E234A. AMPylation transfers AMP of ATP molecule to Tyr/Thr/Ser residues from target protein and leaves the PPi (inorganic pyrophosphate).

This work provided the theoretical evidence for the exact role of the inhibitory glutamate. And HYPE as the first human Fic protein, HYPE-catalyzed mechanism provides a new understanding of the Fic proteins. Our findings also provide a basis to consider further possible alternative cofactors of HYPE and distinct modes of target-recognition.

\section{Computational Details}

\subsection{Models}

Cluster models including chain A of the HYPE (PDB Code: 4U07) [20] crystal structure and the targeted BiP protein (PDB Code: 5O4P) [36] were built based on two X-ray crystal structures (Figure 6 and Figure S5). First, the 30 putative orientations of BiP docked to HYPE were obtained by Z-dock software [37]. Geometry analysis and experimental information $[1,38]$ supported that Thr $518[2,4,5,20,33,38,39]$ as the structurally preferred modification site. Taking the positions of active site His363 [4,5,20,33] and Thr518 as the criteria, the rational docking structures were selected as the starting geometry. Molecular dynamics (MD) simulations for the two geometries, Glu234 and Glu234Ala variants, of the HYPE complex with BiP were performed. The first geometry (Figure $4 \mathrm{~b}$ ) used wild-type HYPE with the Glu234 of the inhibitory $\alpha$-helix. His363 was designated HiD and the potential proton acceptor in the AMPylation reaction. The second geometry (Figure 4c) was built based on the first geometry, with Glu234 mutated to an alanine. All water molecules were removed. The protonation states of the protein were determined using PropKa [40] and visual inspection. After adding hydrogen atoms and missing heavy atoms, the entire system was solvated in a rectangular box by using TIP3P-Ewald water with a distance between the protein and the box boundary of $10.0 \AA$ [41]. Counter ions $\mathrm{Na}^{+} / \mathrm{Cl}^{-}$were added to the box to neutralize the system. Following minimization, both systems were heated from $0 \mathrm{~K}$ to $300 \mathrm{~K}$ for $50 \mathrm{ps}$. Next, a $10 \mathrm{~ns}$ simulation in the canonical ensemble was submitted to equilibration at $300 \mathrm{~K}$. Then, the whole system was subjected to a $70 \mathrm{~ns}$ simulation in the NPT ensemble with a 2 fs time step until the RMSD of the systems converged. All molecular dynamics (MD) simulations were performed using the AMBER suite program [42] and Amber ff14SB force field [43]. Then, final snapshots of the MD simulations were used as the starting points for selecting the QM models [44,45]. In addition, the cluster model consists of the ATP molecule and the metal center $\mathrm{Mg}^{2+}$. Since previous work found that the coordination sphere of $\mathrm{Mg}^{2+}$ has a profound impact on the catalytic reaction $[44,45]$, it is important to examine the coordination environment of $\mathrm{Mg}^{2+}$. In addition, All the boundary $\mathrm{C}$ atoms of the QM parts saturated with hydrogen atoms. And all the hydrogen atoms were added manually. The total numbers of atoms for 
Model-1, Model-2 and Model-3 are 169, 209 and 224, respectively. All the QM models have a net charge of $+1 \mathrm{e}$. To maintain the overall structure of the active site, the boundary carbon atoms and the captured hydrogen atoms were fixed at their corresponding positions in the crystal structure during geometry optimization.
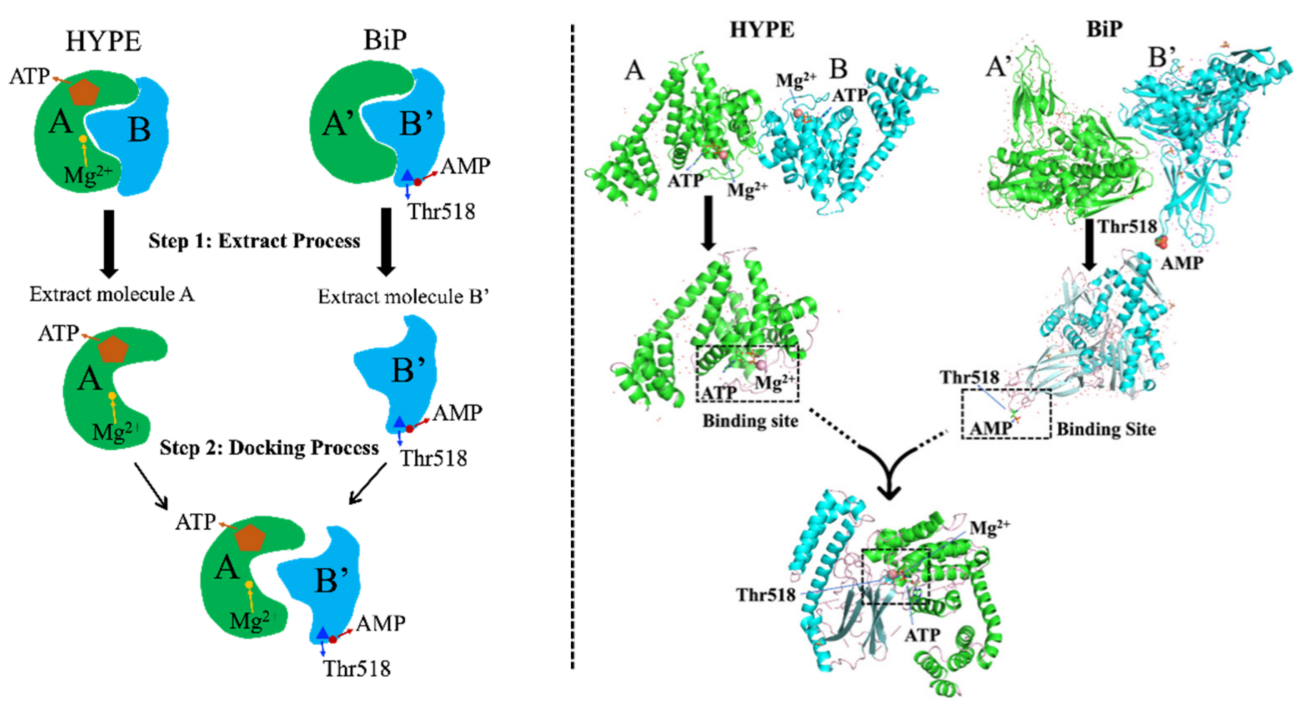

Figure 6. An illustration of Model building using HYPE protein and the substrate BiP protein. Schematic diagram (left column) and Protein structures (right column).

\subsection{Methods}

The geometries of all the minima and transition states were determined by using the hybrid B3LYP [32,46-48] functional with the 6-31g $(\mathrm{d}, \mathrm{p})[49,50]$ basis set for all atoms. Vibrational frequencies were then obtained at the same level of theory to verify all the stationary points as local minima (zero imaginary frequencies) or first-saddle points (one imaginary frequency). IRC [51,52] calculations were also performed to identify the connection between transition states and minima. Based on the frequency calculations, the zero-point energy (ZPE) was also obtained. More accurate energies were further evaluated by the B3LYP functional with larger basis sets 6-311++g $(\mathrm{d}, \mathrm{p})$ for $\mathrm{Mg}^{2+}$ and cc-pVTZ for the rest. The van der Waals (VDW) effect was assessed by using Grimme's D3 protocol [53]. The SMD model with a dielectric constant of 4 was used to mimic the protein environment during energy corrections [54,55]. All DFT calculations were implemented with the Gaussian09 software package [56].

To further study the exact role of the inhibitory glutamate in the AMPylation reaction of the HYPE protein, with the targeted BiP protein. We carried out MD simulations. Energy minimization and MD simulation were performed by using the sander module in the Amber14 program with the Amber ff14SB force field [57-59]. After 2000 steps of energy minimization for the entire system (1000 steepest descent steps and 1000 conjugate gradient steps), MD simulations were performed in the NPT ensemble at 1 bar pressure and a temperature of $300 \mathrm{~K}$. The RMSD analysis and the RMSF analysis were carried out by the cpptraj module in the Amber14 program [57].

Supplementary Materials: The following are available online at https:/ /www.mdpi.com/article/10 $.3390 /$ ijms22136999/s1.

Author Contributions: M.L. performed the calculations. M.L and Z.H. made the analysis and plots. M.L. wrote the paper. H.T. and G.C. helped M.L. to write the paper. All authors have read and agreed to the published version of the manuscript. 
Funding: This work was supported by grants from the National Natural Science Foundation of China (no. 22073010, 21571019 and 21573020) and the National Key Research and Development Program of China (no. 2019YFC1805600). M. Liu thanks the China Scholarship Council for a visiting scholar fellowship. We thank X. Tang, Qingdao University and K. Chen and other group members from University of California, Berkeley, for the language modification and suggestions in the manuscript.

Institutional Review Board Statement: Not applicable.

Informed Consent Statement: Not applicable.

Data Availability Statement: The data presented in this study are available on request from the corresponding author.

Conflicts of Interest: The authors declare no conflict of interest.

\section{References}

1. Casey, A.K.; Orth, K. Enzymes Involved in AMPylation and deAMPylation. Chem. Rev. 2018, 118, 1199-1215. [CrossRef] [PubMed]

2. Ham, H.; Woolery, A.R.; Tracy, C.; Stenesen, D.; Krämer, H.; Orth, K. Unfolded protein response-regulated Drosophila Fic (dFic) protein reversibly AMPylates BiP chaperone during endoplasmic reticulum homeostasis. J. Biol. Chem. 2014, 289, 36059-36069. [CrossRef] [PubMed]

3. Sanyal, A.; Chen, A.J.; Nakayasu, E.S.; Lazar, C.S.; Zbornik, E.A.; Worby, C.A.; Koller, A.; Mattoo, S. A novel link between fic (filamentation induced by cAMP)-mediated adenylylation/AMPylation and the unfolded protein response. J. Biol. Chem. 2015, 290, 8482-8499. [CrossRef] [PubMed]

4. Preissler, S.; Rato, C.; Chen, R.; Antrobus, R.; Ding, S.; Fearnley, I.M.; Ron, D. AMPylation matches BiP activity to client protein load in the endoplasmic reticulum. eLife 2015, 4, 1-33. [CrossRef] [PubMed]

5. Preissler, S.; Rato, C.; Perera, L.A.; Saudek, V.; Ron, D. FICD acts bifunctionally to AMPylate and de-AMPylate the endoplasmic reticulum chaperone BiP. Nat. Struct. Mol. Biol. 2017, 24, 23-29. [CrossRef] [PubMed]

6. Brown, M.S.; Segal, A.; Stadtman, E.R. Modulation of glutamine synthetase adenylylation and deadenylylation is mediated by metabolic transformation of the P II -regulatory protein. Proc. Natl. Acad. Sci. USA 1971, 68, 2949-2953. [CrossRef] [PubMed]

7. O'Shea, J.J.; Holland, S.M.; Staudt, L.M. JAKs and STATs in Immunity, Immunodeficiency, and Cancer. N. Engl. J. Med. 2013, 368, 161-170. [CrossRef] [PubMed]

8. Kingdon, H.S.; Shapiro, B.M.; Stadtman, E.R. Regulation of glutamine synthetase. 8. ATP: Glutamine synthetase adenylyltransferase, an enzyme that catalyzes alterations in the regulatory properties of glutamine synthetase. Proc. Natl. Acad. Sci. USA 1967, 58, 1703-1710. [CrossRef] [PubMed]

9. Vops, V.; Effector, D. AMPylation of Rho GTPases by. Science 2009, 323, 269-272.

10. Worby, C.A.; Mattoo, S.; Kruger, R.P.; Corbeil, L.B.; Koller, A.; Mendez, J.C.; Zekarias, B.; Lazar, C.; Dixon, J.E. The Fic Domain: Regulation of Cell Signaling by Adenylylation. Mol. Cell 2009, 34, 93-103. [CrossRef]

11. Woolery, A.R.; Luong, P.; Broberg, C.A.; Orth, K. Ampylation: Something old is new again. Front. Microbiol. 2010, 1, 2-7. [CrossRef]

12. Kawamukai, M.; Matsuda, H.; Fujii, W.; Nishida, T.; Izumoto, Y.; Himeno, M.; Utsumi, R.; Komano, T. Cloning of the fic-1 gene involved in cell filamentation induced by cyclic AMP and construction of a delta fic Escherichia coli strain. J. Bacteriol. 1988, 170, 3864-3869. [CrossRef]

13. Komano, T.; Utsumi, R.; Kawamukai, M. Functional analysis of the fic gene involved in regulation of cell division. Res. Microbiol. 1991, 142, 269-277. [CrossRef]

14. Garcia-Pino, A.; Zenkin, N.; Loris, R. The many faces of Fic: Structural and functional aspects of Fic enzymes. Trends Biochem. Sci. 2014, 39, 121-129. [CrossRef]

15. Harms, A.; Stanger, F.V.; Dehio, C. Biological Diversity and Molecular Plasticity of FIC Domain Proteins. Annu. Rev. Microbiol. 2016, 70, 341-360. [CrossRef]

16. Hedberg, C.; Itzen, A. Molecular perspectives on protein adenylylation. ACS Chem. Biol. 2015, 10, 12-21. [CrossRef]

17. Faber, P.W.; Barnes, G.T.; Srinidhi, J.; Chen, J.; Gusella, J.F.; MacDonald, M.E. Huntingtin interacts with a family of WW domain proteins. Hum. Mol. Genet. 1998, 7, 1463-1474. [CrossRef]

18. Engel, P.; Goepfert, A.; Stanger, F.V.; Harms, A.; Schmidt, A.; Schirmer, T.; Dehio, C. Adenylylation control by intra-or intermolecular active-site obstruction in Fic proteins. Nature 2012, 482, 107-110. [CrossRef]

19. Khater, S.; Mohanty, D. In silico identification of AMPylating enzymes and study of their divergent evolution. Sci. Rep. 2015, 5, 1-17. [CrossRef]

20. Bunney, T.D.; Cole, A.R.; Broncel, M.; Esposito, D.; Tate, E.W.; Katan, M. Crystal structure of the human, FIC-domain containing protein HYPE and implications for its functions. Structure 2014, 22, 1831-1843. [CrossRef]

21. Goehler, H.; Lalowski, M.; Stelzl, U.; Waelter, S.; Stroedicke, M.; Worm, U.; Droege, A.; Lindenberg, K.S.; Knoblich, M.; Haenig, C.; et al. A protein interaction network links GIT1, an enhancer of huntingtin aggregation, to Huntington's disease. Mol. Cell 2004, 15, 853-865. [CrossRef] [PubMed] 
22. Xiao, J.; Worby, C.A.; Mattoo, S.; Sankaran, B.; Dixon, J.E. Structural basis of Fic-mediated adenylylation. Nat. Struct. Mol. Biol. 2010, 17, 1004-1010. [CrossRef] [PubMed]

23. Muller, M.P.; Peters, H.; Blümer, J.; Blankenfeldt, W.; Goody, R.S.; Itzen, A. The Legionella effector protein DrrA AMPylates the membrane traffic regulator Rab1b. Science 2010, 329, 946-949. [CrossRef] [PubMed]

24. Roy, C.R.; Mukherjee, S. Bacterial FIC proteins AMP up infection. Sci. Signal. 2009, 2, 15-18. [CrossRef]

25. Lewallen, D.M.; Sreelatha, A.; Dharmarajan, V.; Madoux, F.; Chase, P.; Griffin, P.R.; Orth, K.; Hodder, P.; Thompson, P.R. Inhibiting AMPylation: A novel screen to identify the first small molecule inhibitors of protein AMPylation. ACS Chem. Biol. 2014, 9, 433-442. [CrossRef]

26. Luong, P.; Kinch, L.N.; Brautigam, C.A.; Grishin, N.V.; Tomchick, D.R.; Orth, K. Kinetic and structural insights into the mechanism of AMPylation by VopS Fic domain. J. Biol. Chem. 2010, 285, 20155-20163. [CrossRef]

27. Gavriljuk, K.; Schartner, J.; Seidel, H.; Dickhut, C.; Zahedi, R.P.; Hedberg, C.; Kötting, C.; Gerwert, K. Unraveling the Phosphocholination Mechanism of the Legionella pneumophila Enzyme AnkX. Biochemistry 2016, 55, 4375-4385. [CrossRef]

28. Mattoo, S.; Durrant, E.; Chen, M.J.; Xiao, J.; Lazar, C.S.; Manning, G.; Dixon, J.E.; Worby, C.A. Comparative analysis of Histophilus somni immunoglobulin-binding protein A (IbpA) with other Fic domain-containing enzymes reveals differences in substrate and nucleotide specificities. J. Biol. Chem. 2011, 286, 32834-32842. [CrossRef]

29. Truttmann, M.C.; Wu, Q.; Stiegeler, S.; Duarte, J.N.; Ingram, J.; Ploegh, H.L. HypE-specific nanobodies as tools to modulate HypE-mediated target AMPylation. J. Biol. Chem. 2015, 290, 9087-9100. [CrossRef]

30. Goody, P.R.; Heller, K.; Oesterlin, L.K.; Müller, M.P.; Itzen, A.; Goody, R.S. Reversible phosphocholination of Rab proteins by Legionella pneumophila effector proteins. EMBO J. 2012, 31, 1774-1784. [CrossRef]

31. Lascu, I.; Gonin, P. The catalytic mechanism of nucleoside diphosphate kinases. J. Bioenerg. Biomembr. 2000, 32, 237-246. [CrossRef]

32. Becke, A.D. Density-functional thermochemistry. III. The role of exact exchange. J. Chem. Phys. 1993, 98, 5648-5652. [CrossRef]

33. Truttmann, M.C.; Ploegh, H.L. rAMPing Up Stress Signaling: Protein AMPylation in Metazoans. Trends Cell Biol. 2017, 27, 608-620. [CrossRef]

34. Roy, C.R.; Cherfils, J. Structure and function of Fic proteins. Nat. Rev. Microbiol. 2015, 13, 631-640. [CrossRef]

35. Murray, J.S.; Politzer, P. The electrostatic potential: An overview. Wiley Interdiscip. Rev. Comput. Mol. Sci. 2011, 1, 153-163. [CrossRef]

36. Preissler, S.; Rohland, L.; Yan, Y.; Chen, R.; Read, R.J.; Ron, D. AMPylation targets the rate-limiting step of BiP's ATPase cycle for its functional inactivation. eLife 2017, 6, 1-28. [CrossRef]

37. Chen, R.; Li, L.; Weng, Z. ZDOCK: An Initial-stage Protein Docking Algorithm. Proteins Struct. Funct. Bioinform. 2003, 52, 80-87. [CrossRef]

38. Broncel, M.; Serwa, R.A.; Bunney, T.D.; Katan, M.; Tate, E.W. Global profiling of huntingtin-Associated protein e (HYPE)-mediated Ampylation through a chemical proteomic approach. Mol. Cell. Proteomics 2016, 15, 715-725. [CrossRef]

39. Sanyal, A.; Zbornik, E.A.; Watson, B.G.; Christoffer, C.; Ma, J.; Kihara, D.; Mattoo, S. Kinetic and structural parameters governing Fic-mediated adenylylation/AMPylation of the Hsp70 chaperone, BiP/GRP78. Cell Stress Chaperon 2021, 1-18. [CrossRef]

40. Li, H.; Robertson, A.D.; Jensen, J.H. Very fast empirical prediction and rationalization of protein pK a values. Proteins Struct. Funct. Genet. 2005, 61, 704-721. [CrossRef]

41. Průša, J.; Cifra, M. Dataset of molecular dynamics simualtion trajectories of amino-acid solutions with various force fields, water models and modified force field parameters. Data Brief 2020, 20, 105483. [CrossRef]

42. Case, D.A.; Berryman, J.T.; Betz, R.M.; Cerutti, D.S.; Cheattham, T.E.; Darden, T.A.; Duke, R.E.; Giese, T.J.; Gohlke, H.; Goetz, A.W.; et al. AMBER 14, University of California, San Francisco. 2014. Available online: http://ambermd.org/doc12/Amber14.pdf (accessed on 20 June 2021).

43. Perez, A.; MacCallum, J.L.; Brini, E.; Simmerling, C.; Dill, K.A. Grid-Based Backbone Correction to the ff12SB Protein Force Field for Implicit-Solvent Simulations. J. Chem. Theory Comput. 2015, 11, 4770-4779. [CrossRef]

44. Wang, S.; Shen, Q.; Chen, G.; Zheng, J.; Tan, H.; Jia, Z. The phosphatase mechanism of bifunctional kinase/phosphatase AceK. Chem. Commun. 2014, 50, 14117-14120. [CrossRef]

45. Zheng, X.; Chen, L.; Li, M.; Lou, Q.; Xia, H.; Wang, P.; Li, T.; Liu, H.; Luo, L. Transgenerational variations in DNA methylation induced by drought stress in two rice varieties with distinguished difference to drought resistance. PLoS ONE 2013, 8, 1-13. [CrossRef]

46. Kiani, F.; Fischer, S. Stabilization of the ADP/Metaphosphate Intermediate during ATP Hydrolysis in Pre-power Stroke Myosin. J. Biol. Chem. 2013, 288, 35569-35580. [CrossRef]

47. Buchachenko, A.L.; Breslavskaya, N.; Chekhonin, V.P.; Arkhangelsky, S.E.; Orlov, A.P.; Kuznetsov, D.A. Phosphate Transfer Enzymes as the Nuclear Spin Selective Nanoreactors. Int. Res. J. Pure Appl. Chem. 2011, 1, 1-15.

48. Pérez-Gallegos, A.; Garcia-Viloca, M.; González-Lafont, À.; Lluch, J.M. A QM/MM study of Kemptide phosphorylation catalyzed by protein kinase A. The role of Asp166 as a general acid/base catalyst. Phys. Chem. Chem. Phys. 2014, 17, 3497-3511. [CrossRef]

49. Francl, M.M.; Pietro, W.J.; Hehre, W.J.; Binkley, J.S.; Gordon, M.S.; DeFrees, D.J.; Pople, J.A. Self-consistent molecular orbital methods. XXIII. A polarization-type basis set for second-row elements. J. Chem. Phys. 1982, 77, 3654-3665. [CrossRef]

50. Hariharan, P.C.; Pople, J.A. The influence of polarization functions on molecular orbital hydrogenation energies. Theor. Chim. Acta 1973, 28, 213-222. [CrossRef]

51. Fukui, K. A formulation of the reaction coordinate. J. Phys. Chem. 1970, 74, 4161. [CrossRef] 
52. Fukui, K. The Path of Chemical Reactions-The IRC Approach. Acc. Chem. Res. 1981, 14, 363-368. [CrossRef]

53. Grimme, S.; Antony, J.; Ehrlich, S.; Krieg, H. A consistent and accurate ab initio parametrization of density functional dispersion correction (DFT-D) for the 94 elements H-Pu. J. Chem. Phys. 2010, 132. [CrossRef] [PubMed]

54. Song, Y.; Mao, J.; Gunner, M.R. Calculation of proton transfers in bacteriorhodopsin bR and M intermediates. Biochemistry 2003, 42, 9875-9888. [CrossRef] [PubMed]

55. Marenich, A.V.; Cramer, C.J.; Truhlar, D.G. Universal solvation model based on solute electron density and on a continuum model of the solvent defined by the bulk dielectric constant and atomic surface tensions. J. Phys. Chem. B 2009, 113, 6378-6396. [CrossRef] [PubMed]

56. Frisch, M.J.; Trucks, G.W.; Schlegel, H.B.; Scuseria, G.E.; Robb, M.A.; Cheeseman, J.R.; Scalmani, G.; Barone, V.; Menucci, B.; Petersson, G.A.; et al. Gaussian 09, Revision B.02; Gaussian Inc.: Wallingford, CT, USA, 2010.

57. Maier, J.A.; Martinez, C.; Kasavajhala, K.; Wickstrom, L.; Hauser, K.E.; Simmerling, C. ff14SB: Improving the Accuracy of Protein Side Chain and Backbone Parameters from ff99SB. J. Chem. Theory Comput. 2015, 11, 3696-3713. [CrossRef] [PubMed]

58. Götz, A.W.; Williamson, M.J.; Xu, D.; Poole, D.; Le Grand, S.; Walker, R.C. Routine microsecond molecular dynamics simulations with AMBER on GPUs. 1. generalized born. J. Chem. Theory Comput. 2012, 8, 1542-1555. [CrossRef] [PubMed]

59. Le Grand, S.; Götz, A.W.; Walker, R.C. SPFP: Speed without compromise-A mixed precision model for GPU accelerated molecular dynamics simulations. Comput. Phys. Commun. 2013, 184, 374-380. [CrossRef] 